\section{Elongation of Hibiscus acetosella Under Well-watered and Drought-stressed Conditions}

\author{
Amanda Bayer ${ }^{1}$ \\ Stockbridge School of Agriculture, University of Massachusetts, 201 Natural \\ Resources Road, Amherst, MA 01003
}

John Ruter and Marc W. van Iersel

Department of Horticulture, University of Georgia, 1111 Miller Plant Sciences Building, The University of Georgia, Athens, GA 30602-7273

Additional index words. evapotranspiration, load cell, herbaceous perennial, container plant production, height control

\begin{abstract}
Controlling the elongation of ornamental plants is commonly needed for shipping and aesthetic purposes. Drought stress can be used to limit elongation, and is an environmentally friendly alternative to plant growth regulators (PGRs). However, growers can be reluctant to expose plants to drought stress because they do not want to negatively affect overall plant quality and marketability. Knowing how and when stem elongation is affected by water availability will help to increase our understanding of how elongation can be controlled without reducing plant quality. Rooted Hibiscus acetosella Welw. ex Hiern. cuttings were grown in a growth chamber set to a 12-hour photoperiod at $25^{\circ} \mathrm{C}$. Two plants of similar size were used for each replication of the study to compare growth under well-watered and drought-stressed conditions. Time lapse photography was used to determine the diurnal patterns of elongation over the course of the replications. Evapotranspiration was measured using load cells. Well-watered and drought-stressed plants had similar diurnal patterns of elongation and evapotranspiration, demonstrating that both follow circadian rhythms and are not just responding to environmental conditions. Stem elongation was greatest at night and coincided with evapotranspiration decreases, with greatest elongation shortly after the onset of darkness. Elongation was minimal between 800 and 1000 HR when evapotranspiration increases. During the drought-stress portion of the replications, elongation of droughtstressed plants was $44 \%$ less than well-watered plants. Final plant height and shoot dry weight for the drought-stressed plants were $21 \%$ and $30 \%$ less than well-watered plants, respectively. Total leaf area, number of leaves, and number of new visible internodes were greater for well-watered plants than drought-stressed plants. Average length of visible internodes and leaf size were similar for drought-stressed and well-watered plants. If growers want to use drought stress for elongation control, they should ensure that plants are drought stressed before the onset of and during the dark period, when most elongation occurs.
\end{abstract}

Controlling plant stem elongation is common in ornamental plant production. Height control is necessary to meet industry standards for target plant height (Fisher and Heins, 1995), to increase plant aesthetics by producing more compact plants (van Iersel and Nemali, 2004) and because compact plants are less expensive to ship (Burnett and van Iersel, 2008). Plant growth regulators are commonly used (Berghage and Heins, 1991; Currey and Lopez, 2011), but are not always desirable as there is growing concern about the use of agrochemicals in production

Received for publication 15 June 2016. Accepted for publication 9 Sept. 2016.

The research was funded by USDA-NIFA-SCRI (award no. 2009-51181-05768).

We thank Bob Teskey, Matthew Chappell, and Sheryl Wells for their suggestions on this manuscript. ${ }^{1}$ Corresponding author. E-mail: abayer10@umass. edu. growers are reluctant to expose their plants to drought stress because they do not want it to negatively affect overall plant quality (Bailey and Whipker, 1998). Sensor-controlled irrigation has been used to precisely control the timing, severity, and duration of drought stress to control elongation of poinsettia (Euphorbia pulcherrima Willd. ex Klotzsch) (Alem et al., 2015). Alem et al. (2015) controlled the height of poinsettia with deficit irrigation by lowering substrate water content to $0.20 \mathrm{~m}^{3} \cdot \mathrm{m}^{-3}$ until plant height was within the desired range to produce a target final height after which substrate water content was increased to $0.40 \mathrm{~m}^{3} \cdot \mathrm{m}^{-3}$. This effectively lowered plant height without negatively impacting plant quality. With the development of wireless sensor networks for irrigation control in commercial greenhouses and nurseries, this technology will be available soon to growers (Kohanbash et al., 2013; Lea-Cox et al., 2013).

Diurnal patterns of elongation have been examined in many plant taxa. Circadian rhythms interact with environmental conditions to determine elongation rates. Stomatal conductance and transpiration are also controlled partly by the plant circadian clock (Farré, 2012). Stem elongation has diurnal patterns (Nozue and Maloof, 2006) and leaf growth is maximal during the day or night, depending on the taxa. Environmental factors can influence the rate of growth, but not the diurnal pattern (Ruts et al., 2012).

Knowing how and when stem elongation is affected by water availability will increase our understanding of how elongation can be controlled through drought stress without reducing plant quality. Our first objective was to quantify diurnal patterns of elongation of $H$. acetosella in response to well-watered and drought-stressed conditions. H. acetosella is a fast-growing herbaceous species with clear growth responses to irrigation volume and substrate water content (Bayer et al., 2013). Understanding the time of day when elongation occurs can be useful in using drought stress as a means of plant elongation control. Our second objective was to quantify the effect of rewatering on the elongation rate of previously droughtstressed plants. The results of this study can be used to determine the optimal time for applying drought stress for elongation control.

\section{Materials and Methods}

Plant material. Research was conducted in a growth chamber at the University of Georgia in Athens, GA, from 17 Feb. to 1 June 2014. Six individual replications, with one well-watered and one drought-stressed plant each, lasted 11 to 19 d. H. acetosella 'Panama Red' (PP20121) terminal cuttings taken from one stock plant or clones of the stock plant were rooted in a peat-perlite substrate (Fafard 1P; Fafard Inc., Agawam, MA) for 5 to $10 \mathrm{~d}$ after which the rooted cuttings were transplanted into $2.4-\mathrm{L}$ containers filled with a peat-perlite substrate (Fafard 1P, Fafard, Inc.). Cuttings were rooted every 10 to $14 \mathrm{~d}$ to have similar size 
plants for each individual replication. Plants were grown in a growth chamber (E-15; Conviron, Winnipeg, Manitoba, Canada) set to a 12-h photoperiod ( 0800 to $2000 \mathrm{HR}$ ) and a constant temperature of $25^{\circ} \mathrm{C}$, similar to the conditions during data collection. Plants were given 5-7 d for root establishment before onset of a replication. Fertilizer was supplied with a nutrient solution (Peters 15-5-15 Cal-Mag; Scotts, Marysville, OH; 15N-2.2P$12.45 \mathrm{~K}$ ) at a rate of $100 \mathrm{mg} \cdot \mathrm{L}^{-1}$ nitrogen as needed.

Treatments and data collection. Two plants similar in size were chosen for each of the six replications of the study. Axillary branches were removed so that only the central shoot remained. For the first three replications, plants were kept well watered for the first 3 to $4 \mathrm{~d}$ of the replication, after which one plant remained well watered while the other was allowed to become drought stressed over the remaining 6 to $11 \mathrm{~d}$, only watering with $\approx 200$ to $400 \mathrm{~mL}$ after wilting occurred. This provided enough water to keep the plants alive, but not to fully rehydrate them. For the next three replications, plants were kept well watered for the first 3 to $6 \mathrm{~d}$ after which one plant remained well watered and the other was allowed to become drought stressed by completely withholding water over the next 6 to $8 \mathrm{~d}$ after which it was again returned to well-watered conditions for an additional 2 to $7 \mathrm{~d}$ to determine if nodes with reduced elongation stayed short or whether nonstressed elongation resumed on rewatering. The total duration of the six replications differed because of differences in elongation rate among replications. Data collection was concluded when the plants grew out of the field of view of the camera.

Well-watered plants were hand watered daily to above a weight of $\approx 1.5 \mathrm{~kg}$ (pot with substrate + plant), which was the weight of the well-watered plants at the start of the replication. The decrease in weight (pot with substrate + plant) of drought-stressed plants from well-watered to wilting conditions was between 0.71 and $0.96 \mathrm{~kg}$, which is a decrease in volumetric water content of $\approx 0.36$ to $0.48 \mathrm{~m}^{3} \cdot \mathrm{m}^{-3}$. Before the start of each replication, plant height, number of internodes, internode lengths, stem diameter, and number of leaves were measured.

The weight of each plant was measured using individually calibrated load cells (LSP10; Transducer Techniques, Temecula, CA) mounted on steel platforms with an acrylic platform on top of each load cell. Plant mass was measured every minute and averages were recorded by the data logger (CR1000; Campbell Scientific, Logan, UT) every $10 \mathrm{~min}$. Hourly evapotranspiration was determined as the decrease in pot weight in $1 \mathrm{~h}$ after correcting for irrigation when needed. Environmental conditions were measured using a temperature and relative humidity sensor (HMP50; Vaisala, San Jose, CA) and a quantum sensor (SQ-110; Apogee Instruments, Logan, UT) with measurements averaged and recorded every $10 \mathrm{~min}$.
Daytime temperature in the growth chamber averaged $25.5{ }^{\circ} \mathrm{C} \pm 0.021$ and night temperature averaged $24.4{ }^{\circ} \mathrm{C} \pm 0.018$. Relative humidity fluctuated both over the course of an individual replication and among replications ranging between $14 \%$ and $65 \%$. Vapor pressure deficit also varied over the course of an individual replication and among replications, ranging between 1.1 and $2.8 \mathrm{kPa}$. Average photosynthetic photon flux density, measured at container height, was $324 \mu \mathrm{mol} \cdot \mathrm{m}^{-2} \cdot \mathrm{s}^{-1}$.

Time lapse photography (Pentax WG-1; RICOH Imaging Company, Denver, CO) was used to take hourly pictures of both plants and a meter stick in the same image. Hourly stem elongation was measured using image analysis software (Image J; U.S. National Institutes of Health; Bethesda, MD). Hourly elongation is the increase in height at the stated hour compared with height at the previous hour (i.e., stem elongation at $2000 \mathrm{HR}$ is the elongation between 1900 and $2000 \mathrm{HR}$ ).

At the conclusion of each replication, height, number of internodes, internode lengths, stem diameter, and number of leaves were recorded. Shoots were cut off at the substrate surface and were dried at $80^{\circ} \mathrm{C}$ after which dry weight was determined. Compactness was calculated as shoot dry weight/shoot length. Leaf area was measured using a leaf area meter (LI-3100; LI-COR, Lincoln, NE) and used to determine total leaf area per plants as well as the average size of all leaves on a plant.

Experimental design and data analysis. The experiment was designed as a randomized complete block with six replications and two plants per replication (one well watered and one drought stressed; $n=6$ ). Experimental units were individual plants. Data were analyzed using the PROC TTEST and PROC MIXED procedures of SAS (SAS Version 9.2; SAS Institute, Cary, NC), with $P \leq 0.05$ considered to be significant. Treatment means were separated using the PDIFF option of PROC MIXED. Regression analysis was done using proc GLM (SAS 9.3; SAS, Cary, NC).

\section{Results and Discussion}

Total height increase was $30 \%$ less for the drought-stressed than the well-watered plants $(P=0.0077)$ over the course of the 11 to $19 \mathrm{~d}$ replications (Table 1). During the droughtstressed period of the replications, elongation of drought-stressed plants was $44 \%$ less than that of the well-watered plants (Fig. 1). Final height of plants that were rewatered was $21 \%$ less than well-watered plants (data not shown). Elongation rate varied by replication (data not shown); likely because of fluctuations in environmental conditions between replications and natural variations in growth. The final number of new visible internodes was higher for well-watered plants than droughtstressed plants $(P=0.054$; Table 1$)$. Droughtstressed and then rewatered plants had $15 \%$ fewer new internodes and drought-stressed only plants had $37 \%$ fewer new internodes than well-watered plants (data not shown). Average length of all visible internodes was similar among treatments $(P=0.51$; Table 1$)$. We hypothesize that the difference in the number of new visible internodes between well watered and drought stressed is due to unelongated, nonvisible internodes near the growing point of the drought-stressed plants. Development and differentiation in the apex is largely temperature driven (Atkinson and Porter, 1996), while elongation is water dependent (Hsiao and $\mathrm{Xu}, 2000$ ); this would mean that new internodes could develop, while drought stress would inhibit elongation of those internodes. Shoot dry weight was $30 \%$ less for the drought-stressed than the well-watered plants $(P=0.037$; Table 1$)$

Drought stress has been used to reduce elongation in many species including Gaura lindheimeri Engelm. \& Gray 'Siskiyou Pink' (Burnett and van Iersel, 2008), Rhododendron 'Catawbiense Boursault' and Rhododendron 'Old Port' (Koniarski and Matysiak, 2013), Tagetes erecta L. 'Queen Sophia' (van Iersel and Nemali, 2004), Salvia splendens F. Sellow. Ex Roem. \& Shult. 'Bonfire' (Burnett et al., 2005), and H. acetosella 'Panama Red' (Bayer et al., 2013). Stem elongation is reduced by drought stress due to reduced cell division and expansion (Hsiao and $\mathrm{Xu}, 2000$ ), which could explain the lower number of visible internodes under drought stress. G. lindheimeri, T. erecta, and $H$. acetosella were smaller, but not more compact, with drought stress. Compactness, shoot dry weight per unit shoot length, is a measure of plant density and an indicator of quality (van Iersel and Nemali, 2004). Compactness of well-watered and droughtstressed plants was not different in this study (Table 1); however, well-watered plants formed more axillary shoots than droughtstressed ones $(P=0.011$; data not shown).

Leaf area and number of leaves were $\approx 36 \%$ lower for drought-stressed than for well-watered plants $(P=0.012$ and $P=0.016$, respectively; Table 1$)$, but the average leaf size was unaffected by drought (Table 1). Reduced leaf area with drought stress has been reported for $G$. lindheimeri (Burnett and van Iersel, 2008), Rhododendron 'Catawbiense Boursault' and Rhododendron 'Old Port' (Koniarski and Matysiak, 2013), S. splendens (Burnett et al., 2005), and T. erecta (van Iersel and Nemali, 2004). Leaf size of $H$. acetosella 'Panama Red' was reduced with decreasing substrate volumetric water content (Bayer et al., 2013). Reduced leaf area of $T$. erecta under drought was the result of fewer leaves and reduced leaf size (van Iersel and Nemali, 2004). Leaf area is reduced with drought stress due to reduced cell elongation with low soil water potential (Hsiao and $\mathrm{Xu}$, 2000; Lambers et al., 2008). The lack of difference in average leaf size in this study was unexpected as leaf size is normally reduced with drought stress. Since wellwatered plants branched more than droughtstressed ones, they may likely also have 
Table 1. Growth measurements for well-watered and drought-stressed Hibiscus acetosella 'Panama Red'. Increase in height is over the course of the 7 to $11 \mathrm{~d}$ drought-stress period. Other measurements are over the course of the 11-19 d replications including the rewatering of stressed plants. Compactness was calculated as shoot dry weight/shoot length $(n=6)$.

\begin{tabular}{|c|c|c|c|c|c|c|c|c|}
\hline Treatment & $\begin{array}{l}\text { Ht increase } \\
(\mathrm{mm})\end{array}$ & $\begin{array}{c}\text { Shoot dry } \\
\text { wt (g) }\end{array}$ & $\begin{array}{l}\text { Compactness } \\
\left(\mathrm{g} \cdot \mathrm{m}^{-1}\right)\end{array}$ & $\begin{array}{l}\text { Avg internode } \\
\text { length }(\mathrm{mm})\end{array}$ & $\begin{array}{c}\text { Number of new visible } \\
\text { internodes }\end{array}$ & $\begin{array}{l}\text { Leaf area } \\
\left(\mathrm{cm}^{2}\right)\end{array}$ & Number of leaves & Avg leaf size $\left(\mathrm{cm}^{2}\right)$ \\
\hline$\overline{\text { Well watered }}$ & 285 & 6.5 & 8.6 & 34.7 & 10 & 1,291 & 101 & 12.8 \\
\hline Drought stressed & 171 & 4.5 & 7.3 & 33.4 & 8 & 808 & 66 & 12.3 \\
\hline$P$ value & 0.0077 & 0.037 & 0.19 & 0.51 & 0.054 & 0.012 & 0.016 & 0.65 \\
\hline
\end{tabular}

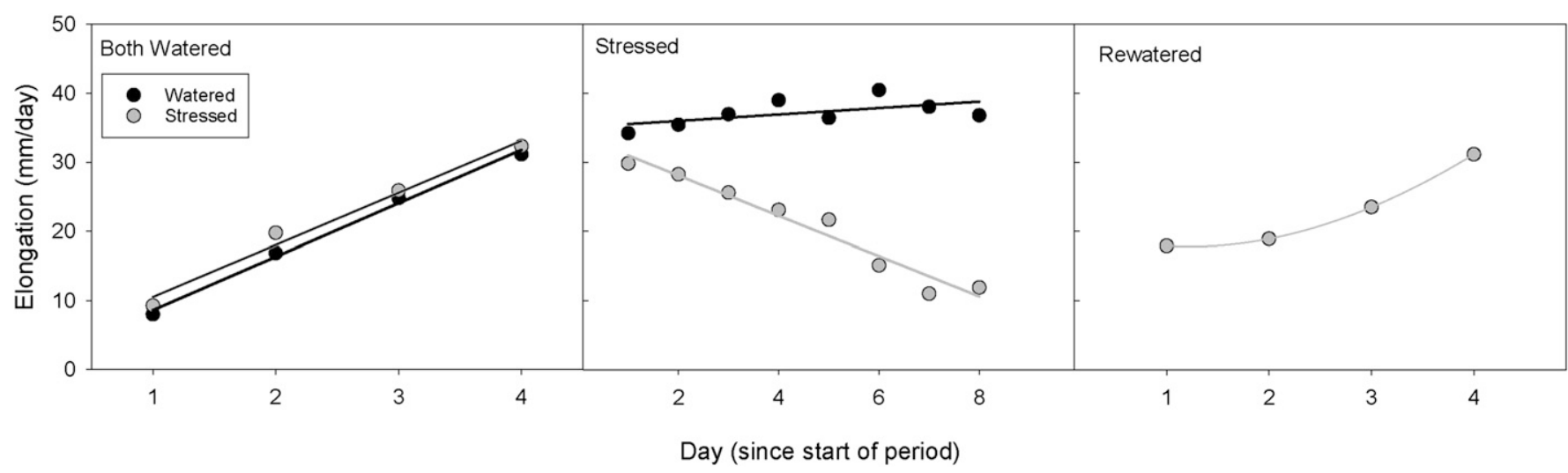

Fig. 1. Daily elongation of Hibiscus acetosella 'Panama Red' over the course of the 11-19 d replications. Graphs have been separated into periods that both plants were watered (left), watered or stressed (middle), and after rewatering of stressed plants (right) to show changes in daily elongation during the different periods. Daily elongation was not different for the plants when both were well watered. After the onset of drought stress, daily elongation rate was greater for well-watered plants than stressed plants $(P<0.0001$; Fig. 1$)$ with the reduction in elongation due to drought stress increasing with days after onset of drought stress. Elongation of previously drought-stressed plants increased gradually during the $4 \mathrm{~d}$ after rewatering.

produced more new leaves. If these new leaves did not fully expand by the end of a trial, the relatively small size of these expanding leaves may have biased the average leaf size of well-watered plants. The increase in stem diameter was similar for drought-stressed and well-watered plants (data not shown).

Daily elongation rate was similar for plants in both treatments during the first $4 \mathrm{~d}$ of a replication when both plants were well watered (Fig. 1). After the onset of drought stress, daily elongation rate was higher for well-watered plants than stressed plants $(P<$ 0.0001 ; Fig. 1) with the reduction in elongation due to drought stress increasing with time after the onset of drought stress $(P=$ 0.019 ; Fig. 1). Daily elongation during the drought-stress period averaged $39.4 \pm 1.7$ and $20.9 \pm 1.8 \mathrm{~mm}$ for well-watered and droughtstressed plants, respectively. Under wellwatered conditions, plant height increased by $\approx 6 \%$ per day. Daily elongation rate for drought-stressed plants was $13 \%$ less than well-watered plants within $2 \mathrm{~d}$ of the onset of drought stress and was 33\% less at the end of the drought-stress period.

Elongation rate of well-watered plants was higher than that of the stressed plants at any time of the day $(P<0.0001)$ within $2 \mathrm{~d}$ of the onset of the drought stress, with both well-watered and drought-stressed plants exhibiting similar diurnal patterns of elongation (Fig. 2). The daytime elongation rate averaged $1.05 \pm 0.21$ and $0.31 \pm 0.041 \mathrm{~mm} / \mathrm{h}$ and nighttime elongation $2.41 \pm 0.20$ and $1.57 \pm 0.12 \mathrm{~mm} / \mathrm{h}$ for well-watered plants and drought-stressed plants, respectively. Elongation rate was lowest between 0800 and
$1000 \mathrm{HR}$ at 0.44 and $0.12 \mathrm{~mm} / \mathrm{h}$ and highest around $2000 \mathrm{HR}$ with elongation rates of 3.53 and $2.87 \mathrm{~mm} / \mathrm{h}$ for well-watered plants and drought-stressed plants, respectively. Elongation rate was relatively steady from 1000 to $1900 \mathrm{HR}$ and from 2100 to $0700 \mathrm{HR}$.

Circadian and diurnal rhythms of stem elongation rates have been reported (Nozue and Maloof, 2006) for plants grown under constant temperature and light as well as light and dark cycles (Dowson-Day and Millar, 1999; Lecharny and Wagner, 1984). Inflorescence stem elongation of Arabidopsis thaliana L. (Jouve et al., 1998) and stem elongation of Chenopodium rubrum (Lecharny and Wagner, 1984) have circadian rhythms even in constant light. Dowson-Day and Millar (1999) reported a diurnal pattern with maximum hypocotyl elongation rates of $A$. thaliana at dusk with reductions in elongation rate at dawn. This is similar to our results with maximum elongation around $2000 \mathrm{HR}$ with a burst of elongation occurring soon after the start of darkness and minimal elongation between 0800 and 1000 HR, the start of the light period. Conversely, Neily et al. (1997) reported stem elongation rate of snapdragon declined at night and increased during the day. Patterns of stem elongation rate of zinnia changed with developmental stage, with elongation rate greatest early in the day during early development and at night as plants matured (Neily et al., 1997). This suggests that stem elongation patterns are species and developmentally dependent. Similarly, leaf elongation rates have been reported to show growth patterns with maximum elongation occurring around dawn or at night depending on species (Ruts et al., 2012).
There was an inverse relationship between elongation and evapotranspiration rate, with evapotranspiration high during the day and low at night and elongation greatest at night (Fig. 2). This suggests that elongation is highest at night due to rehydration when stomata close at night and increasing turgor pressure of the plant, allowing for cell elongation. Sufficient turgor pressure is needed to plastically stretch the cell well allowing for cell expansion (Boyer and Silk, 2004; Passioura and Boyer, 2003). Evapotranspiration was low when the lights were off, increasing rapidly between 0800 and $0900 \mathrm{HR}$ after the lights were turned on and rapidly decreasing between 2000 and $2100 \mathrm{HR}$ after the lights were turned off, indicative of stomatal opening in response to light. Elongation was highest between 2000 and $2100 \mathrm{HR}$ and was $59 \%$ and $82 \%$ higher at night than during the day for the well-watered and drought-stressed plants, respectively. Elongation rate began to decrease at around $0700 \mathrm{HR}$ (before the start of the light period), suggesting that elongation is responding to a circadian pattern rather than just a response to light. Lower transpiration rates at night could mean that more water is available for cell expansion and elongation, rather than transpiration, which could explain greater nighttime elongation. A comparison of daily evapotranspiration and elongation shows the reduction in elongation rate due to drought stress $(P=0.01)$. Rewatering drought-stressed plants rapidly increased evapotranspiration $(P<0.0001$; Fig. 3$)$; however, elongation rate remained restricted and gradually increased from 18 to $30 \mathrm{~mm} \cdot \mathrm{d}^{-1}$ during the $4 \mathrm{~d}$ after rewatering (Fig. 1). This suggests that drought 


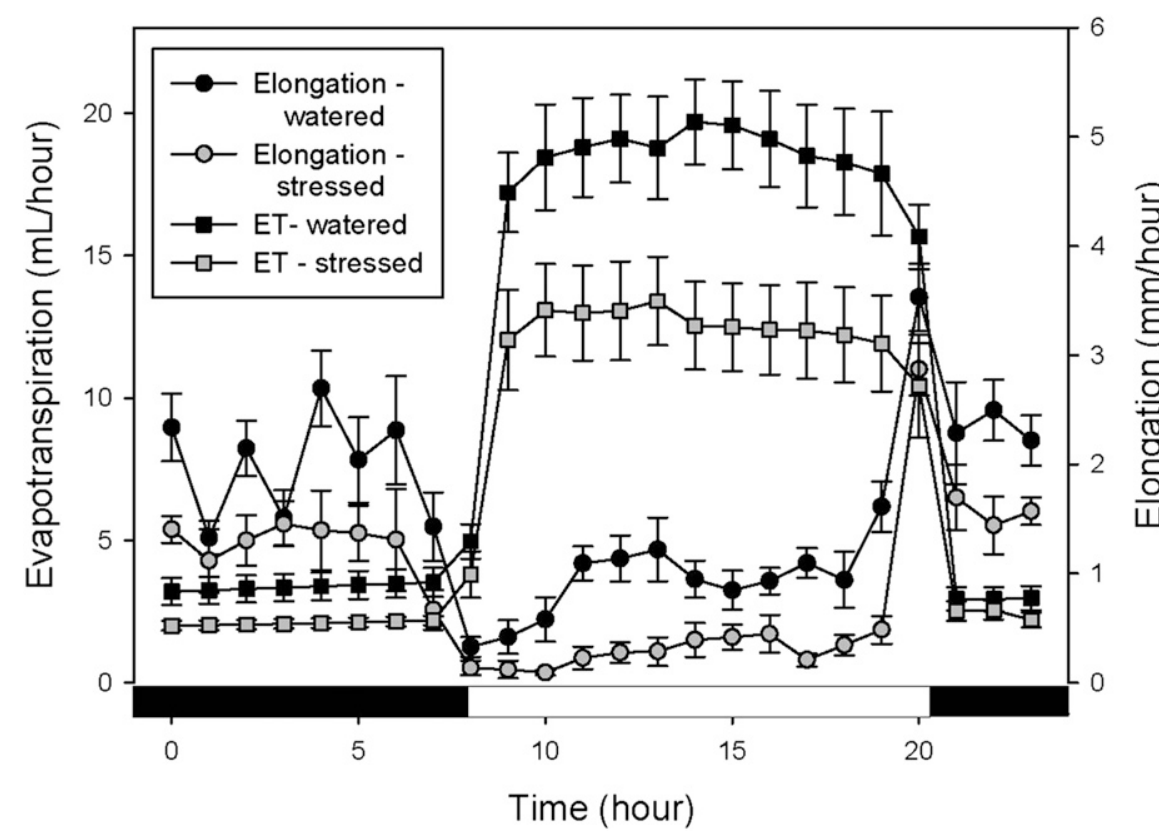

Fig. 2. Hourly evapotranspiration (ET, squares) and elongation (circles) of Hibiscus acetosella 'Panama Red' over the course of $24 \mathrm{~h}$ for the 11-19 d replications. Data for drought-stressed plants begins $1 \mathrm{~d}$ after the onset of drought. A diurnal pattern of ET can be seen with increased ET when the lights are turned on (0800 HR) and decreased when the lights are turned off (2000 HR). Elongation also exhibits a diurnal pattern with reduced elongation during the day and increased elongation at night. For both ET and elongation, well-watered and drought-stressed plants follow similar diurnal patterns with droughtstressed plants having reduced ET and elongation. Elongation and ET data at a specific time indicate the elongation and ET during the previous hour. Black and white boxes at the bottom of the graph indicate darkness and light, respectively. Error bars indicate standard errors.

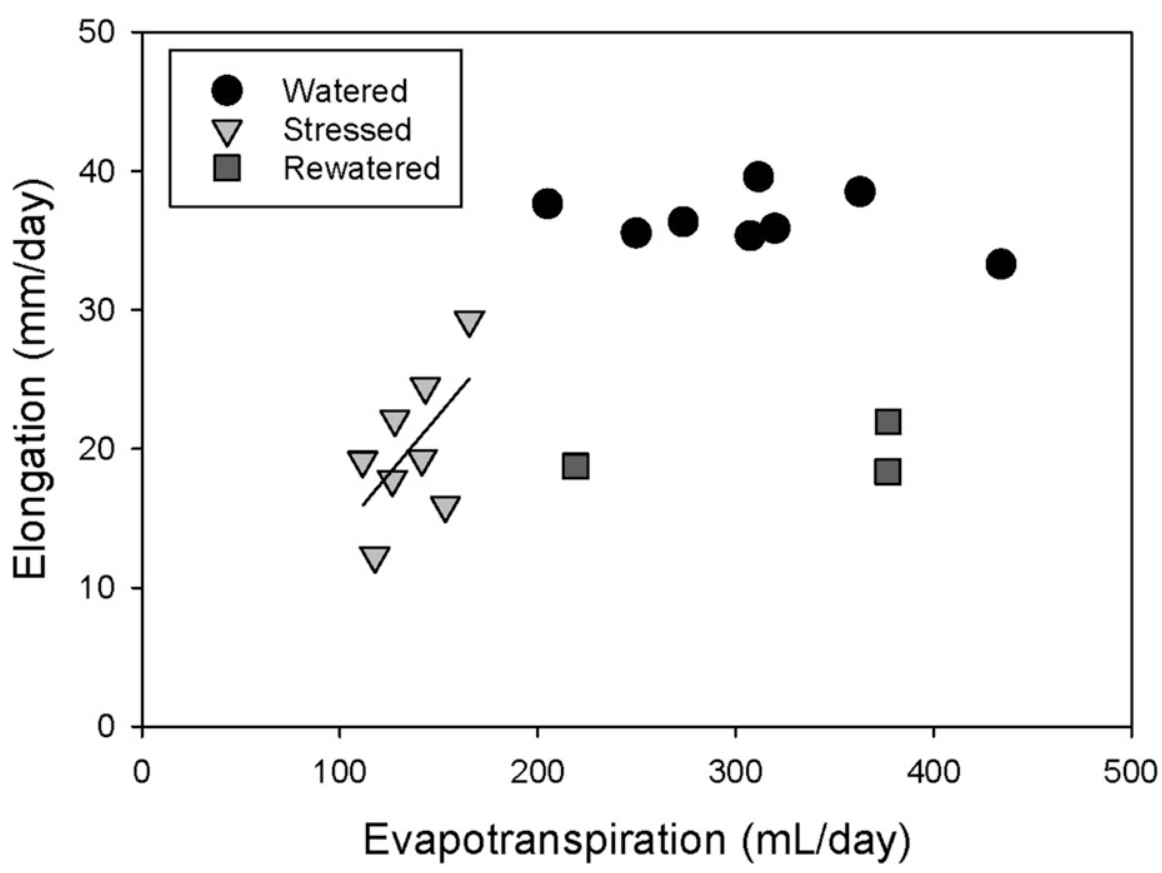

Fig. 3. Daily elongation of well-watered (black circles), drought-stressed (light gray triangles), and stressed then rewatered (dark gray squares) Hibiscus acetosella 'Panama Red' as a function of daily evapotranspiration. The relationship between evapotranspiration and elongation shows that as drought stress reduces evapotranspiration, the elongation rate is reduced as well $(P=0.01)$. Rewatering stressed plants resulted in increased evapotranspiration; however, elongation rate remained low.

causes temporary changes in cell wall plasticity that prevent rapid elongation after the drought stress has been relieved. Such a lasting effect of drought stress on elongation of leaves of dicots has been reported previously (Granier and Tardieu, 2009).

Evapotranspiration is influenced by environmental conditions including light, temperature, and vapor pressure deficit, but also by stomatal opening and closing, which is regulated partly by circadian mechanisms (Hotta et al., 2007). In well-watered A. thaliana plants, stomata close at midday, not in response to water status but due to circadian control of the guard cells (Dodd et al., 2005). Stomata also open in anticipation of dawn (Hotta et al., 2007) indicating circadian control. Evapotranspiration began to increase around $0700 \mathrm{HR}$ and decrease around $1900 \mathrm{HR}$, an hour before lights were turned on and off, respectively. This could suggest stomatal opening and closing in anticipation of dawn and dusk. Diurnal changes in transpiration can be due to changes in abscisic acid (ABA) levels, which are influenced by the circadian clock (Tallman, 2004). Environmental influences can alter the intensity of the circadian responses (Hotta et al., 2007). Reduced leaf area surface of drought-stressed plants contributes to reduced transpiration (Obidiegwu et al., 2015; Patanè, 2011). The combination of increased ABA levels, reduced leaf area, and drought stress could explain reduced evapotranspiration in drought-stressed plants.

\section{Conclusions}

Both drought-stressed and well-watered plants followed a similar diurnal pattern of elongation, agreeing with previous research that elongation depends on a circadian rhythm and is not only a response to environmental conditions. Well-watered plants elongated $10 \mathrm{~mm} \cdot \mathrm{d}^{-1}$ more than droughtstressed plants. Daily elongation showed that as the severity of drought stress increased over the course of the study, the rate of elongation of the drought-stressed plants continued to decrease. Results of this study show that controlling stem elongation and growth of plants is possible with irrigation management. In this study, diurnal patterns show that elongation of $H$. acetosella is greatest at night, with greatest elongation following the onset of darkness when evapotranspiration decreased. Elongation is minimal between 0800 and 1000 HR when evapotranspiration increases. If growers want to use drought stress for elongation control, they should ensure that plants are drought stressed before the onset of and during the dark period, when most elongation occurs. It is also important to consider that the effects of drought stress on elongation can persist after the drought stress has been relieved.

\section{Literature Cited}

Alem, P.O., P.A. Thomas, and M.W. van Iersel. 2015. Use of controlled water deficit to regulate poinsettia stem elongation. HortScience 50: 234-239.

Atkinson, D. and J.R. Porter. 1996. Temperature, plant development and crop yields. Trends Plant Sci. 1:119-124.

Bailey, D. and B. Whipker. 1998. Height control of commercial greenhouse flowers. Hort. Info. Lflt. 528, N.C. Coop. Ext. Serv.

Bayer, A., I. Mahbub, M. Chappell, J. Ruter, and M.W. van Iersel. 2013. Water use and growth 
of Hibiscus acetosella 'Panama Red' grown with a soil moisture sensor-controlled irrigation system. HortScience 48:980-987.

Berghage, R.D. and R.D. Heins. 1991. Quantification of temperature effects on stem elongation of poinsettia. J. Amer. Soc. Hort. Sci. 116:14-18.

Boyer, J.S. and W.K. Silk. 2004. Hydraulics of plant growth. Funct. Plant Biol. 31:761-773.

Burnett, S., P. Thomas, and M. van Iersel. 2005. Post-germination drenches with PEG-8000 reduce growth of saliva and marigolds. HortScience 40:675-679.

Burnett, S.E. and M.W. van Iersel. 2008. Morphology and irrigation efficiency of Gaura lindheimeri grown with capacitance sensor-controlled irrigation. HortScience 43:1555-1560.

Currey, C.J. and R.G. Lopez. 2011. Early flurprimidol drench applications suppress final height of four poinsettia cultivars. HortTechnology 21:35-40.

Dodd, A.N., N. Salathia, A. Hall, E. Kévei, R. Tóth, F. Nagy, J.M. Bibberd, A.J. Millar, and A.A.R. Webb. 2005. Plant circadian clocks increase photosynthesis, growth, survival, and competitive advantage. Science 309:630-633.

Dowson-Day, M. and A.J. Millar. 1999. Circadian dysfunction causes aberrant hypocotyl elongation patterns in Arabidopsis. Plant J. 17:63-71.

Ecke, P., III, J.E. Jaust, J. Wiggins, and A. Higgins. 2004. Height control, p. 51-72. In: The Ecke poinsettia manual. Ball Publishing, Batavia, IL.

Farré, E.M. 2012. The regulation of plant growth by the circadian clock. Plant Biol. 14:401-410.

Fisher, P.R. and R.D. Heins. 1995. A processcontrol approach to poinsettia height control. HortTechnology 5:57-63.

Granier, C. and F. Tardieu. 2009. Multi-scale phenotyping of leaf expansion in response to environmental changes: The whole is more than the sum of parts. Plant Cell Environ. 32:1175-1184.

Hotta, C.T., M.J. Gardner, K.E. Hubbard, S.J. Baek, N. Dalchau, D. Suhita, A.N. Dodd, and A.A.R. Webb. 2007. Modulation of environmental responses of plants by circadian clocks. Plant Cell Environ. 30:333-349.

Hsiao, T.C. and L.K. Xu. 2000. Sensitivity of growth of roots versus leaves to water stress: Biophysical analysis and relation to water transport. J. Expt. Bot. 51:1595-1616.

Jouve, L., H. Geppin, and R.D. Agosti. 1998. Arabidopsis thaliana floral stem elongation: Evidence for an endogenous circadian rhythm. Plant Physiol. Biochem. 36:469-472.

Kaufmann, P.H., R.J. Joly, and P.A. Hammer. 2000. Influence of day and night temperature differentials on root elongation rate, root hydraulic properties, and shoot water relations in chrysanthemum. J. Amer. Soc. Hort. Sci. 125:383-389.

Kohanbash, D., G. Kantor, T. Martin, and L. Crawford. 2013. Wireless sensor network design for monitoring and irrigation control: User-centric hardware and software development. HortTechnology 23:725-734.

Koniarski, M. and B. Matysiak. 2013. Growth and development of potted Rhododendron cultivars 'Catawbiense Boursault' and 'Old Port' in response to regulated deficit irrigation. J. Hort. Res. 21:29-37.

Lambers, H., T.L. Pons, and S. Chapin. 2008. Plant physiological ecology. 2nd ed. Springer Verlag, New York, NY.

Lea-Cox, J.D., W.L. Bauerle, M.W. van Iersel, G. F. Kantor, T.L. Bauerle, E. Lichtenberg, D.M. King, and L. Crawford. 2013. Advancing wireless sensor networks for irrigation management of ornamental crops: An overview. HortTechnology 23:717-724.

Lecharny, A. and E. Wagner. 1984. Stem extension rate in light-grown plants. Evidence for an endogenous circadian rhythm in Chenopodium rubrum. Physiol. Plant. 60:437-443.

Liu, B. and R.D. Heins. 2002. Photothermal ratio affects plant quality in 'Freedom' poinsettia. J. Amer. Soc. Hort. Sci. 127:20-26.

Neily, W.G., P.R. Hicklenton, and D.N. Kristie. 1997. Temperature and developmental stage influence diurnal rhythms of stem elongation in Snapdragon and Zinnia. J. Amer. Soc. Hort. Sci. 122:778-783.

Nozue, K. and J.N. Maloof. 2006. Diurnal regulation of plant growth. Plant Cell Environ. 29: 396-408.

Obidiegwu, J.E., G.J. Bryan, H.G. Jones, and A. Prashar. 2015. Coping with drought: Stress and adaptive responses in potato and perspectives for improvement. Front. Plant Sci. 6:542.

Passioura, J.B. and J.S. Boyer. 2003. Tissue stresses and resistance to water flow conspire to uncouple the water potential of the epidermis from that of the xylem in elongating plant stems. Funct. Plant Biol. 30:325-334.

Patanè, C. 2011. Leaf area index, leaf transpiration and stomatal conductance as affected by soil water deficit and VPD in processing tomato in semi arid Mediterranean climate. J. Agron. Crop Sci. 197(3):165-176.

Ruts, T., S. Matsubara, A. Wiese-Klinkenberg, and A. Walter. 2012. Diel patterns of leaf and root growth: Endogenous rhythmicity or environmental response? J. Expt. Bot. 63:3339-3351.

Tallman, G. 2004. Are diurnal patterns of stomatal movement the result of alternating metabolism of endogenous guard cell ABA and accumulation of ABA delivered to the apoplast around guard cells by transpiration? J. Expt. Bot. 55:1963-1976.

van Iersel, M.W. and K.S. Nemali. 2004. Drought stress can produce small but not compact marigolds. HortScience 39:1298-1301. 